Pecvnia, 9 (2009), pp. 43-62

\title{
Análisis de las discrepancias económicas entre Swanston y Cia, constructora del Puerto de la Luz (Canarias), y su ingeniero Juan de León y Castillo ${ }^{*}$
}

Recibido: Abril 2009 Aceptado: Julio 2009
Mercedes Calvo Cruz

mcalvo@defc.ulpgc.es

Candelaria Castro Pérez

ccastro@defc.ulpgc.es

Universidad de Las Palmas de Gran Canaria

Fac. de Ciencias Económicas y Empresariales

Dpto. de Economía Financiera y Contabilidad

Campus de Tafira

35017 Las Palmas de Gran Canaria (España)
En este trabajo pretendemos abordar la figura de Juan de León y Castillo, persona ilustre en su época, científico, ingeniero y apasionado por la política y la filosofía, desde una óptica novedosa, toda vez, que se pretende poner de manifiesto la estrecha relación que existió entre el ingeniero y la Swanston and Company, contratista que llevó a cabo la construcción del Puerto de Refugio de la Luz de Las Palmas. Esta relación
In this work we try to approach Juan de León y Castillo's figure, an illustrious person of his time, scientist, engineer and an enthusiast about politics and philosophy. From a new optic, he tried to reveal the narrow relation that existed between the engineer and the Swanston and Company, contractor who carried out the construction of El Puerto de Refugio de la Luz de Las Palmas. This relation dates back on the

Este trabajo forma parte de un proyecto becado por el Cabildo de Gran Canaria: Beca de Investigación "León y Castillo" 2007. 
data de 1891, momento en el que se firma el contrato entre ambos y Juan de León y Castillo se hace cargo de las obras del puerto como Ingeniero Director y Consultivo.

Es nuestro objetivo evidenciar los entresijos económicos y los numerosos problemas que existieron entre el ingeniero y la empresa contratista y poner de manifiesto una desconocida faceta de Juan de León y Castillo como censor de los libros contables y demás documentación económica que la Swanston llevaba para la obra que nos ocupa.

Por tanto, con este trabajo quisiéramos contribuir al conocimiento de un hombre ilustre y polifacético, que no sólo se dedicó a la estricta labor de desarrollar aquellos conocimientos recibidos sino que denota la curiosidad propia de un investigador y la ecuanimidad en su proceder.

Palabras clave: Historia de la Contabilidad; Puerto; Contrato. late 1891 , moment in which the contract is signed between both and Juan de León y Castillo takes charge of the works of the port as an engineer, director and advisor.

It is our aim to demonstrate the economic mesenteries and the numerous problems which existed between the engineer and the company contractor and to reveal an unknown facet of Juan de León y Castillo as critic of the account books and other economic documentation that the Swanston was taking for the work that occupies us.

Therefore, with this work we wanted to contribute to the knowledge of an illustrious and versatile man, who not only devoted itself to the strict labour of developing those received knowledge's but it denotes the curiosity of a researcher and the equanimity in his proceedings.

Key words: history, accounting, port, contract/ agreement.

\section{INTRODUCCIÓN}

La prolífica figura de Juan de León y Castillo es consecuencia de sus inquietudes en el ámbito político, filosófico y científico que han dado lugar a diversas obras escritas como son, entre otras: Ciencia y política en el pensamiento de Juan de León y Castillo y "Juan de León y Castillo y las sociedades científicas, literarias, artísticas o de recreo de su tiempo" ambas de Martín del Castillo en 1993; y diversas biografías entre las que destacamos la de Millares Torres Biografías de Canarios célebres en 1982 y las publicadas por Hernández Gutiérrez, Juan de León y Castillo: ingeniero, científico y humanista en 1995 y Juan de León y Castillo en 2006.

Asimismo, otros trabajos se han centrado en sus obras de ingeniería entre los que se encuentran los divulgados por Martín del Castillo: "Ingeniería en Canarias, 1850-1900: Juan de León y Castillo" (1995), "Un aparato de gasolina diseñado por Juan de León y Castillo para el alumbrado de Las Palmas de Gran Canaria" (1997), "El ingeniero Juan de León y Castillo y los ferrocarriles de Barcelona (1886-1890)" (2003) y "Juan de León y Castillo: planos para una historia iconográfica de la ingeniería 
canaria: aproximación al diseño técnico del siglo pasado" (2003). Además existen otras publicaciones en torno a su gran obra como fue el Puerto de Refugio de la Luz de Las Palmas, en este sentido hemos de citar las siguientes: La Tipografía del Diario (1909), Moreno (1935), Suárez Falcón (1952), Burriel de Orueta (1974) y Hernández Gutiérrez (1991).

No obstante, existe una faceta desconocida de Juan de León y Castillo como es la función de censor de la documentación contable generada por la empresa Swanston y Cia., contratista de las obras de construcción del Puerto de Refugio de La Luz de Las Palmas, con quien firmó un contrato para dirigir las citadas obras. Con este trabajo quisiéramos contribuir al conocimiento de este hombre ilustre y polifacético, que no sólo se dedicó a la estricta labor de desarrollar aquellos conocimientos recibidos sino que denota la curiosidad propia de un investigador y la ecuanimidad en su proceder.

Por tanto, es nuestro objetivo evidenciar los entresijos económicos y los numerosos problemas que existieron entre ambas partes como consecuencia del contrato que les vinculaba y que el ingeniero puso de manifiesto al detectar discrepancias tanto en las cláusulas del mismo como en su posterior aplicación, circunstancias que afectaron a sus intereses económicos y que encontró reflejadas en la contabilidad.

Este estudio ha sido posible gracias a la información generada por el propio Juan de León y Castillo en su relación con la Swanston al analizar la documentación facilitada por la constructora, dando lugar al fondo histórico "Ingeniero D. Juan de León y Castillo", localizado en el Archivo Histórico Provincial de Las Palmas "Joaquín Blanco", constituyendo nuestra principal fuente de información primaria.

El presente trabajo se encuadra dentro de la línea de investigación Historia de la Contabilidad, presentando los análisis que realizó Juan de León y Castillo sobre la contabilidad de las obras del puerto generada por la empresa contratista Swanston y Cia., con la particularidad de revisar el ingeniero una contabilidad privada que él no había elaborado.

Finalmente, señalar que la época a la cual va referida este estudio se corresponde con finales del siglo XIX y principios del XX, periodo que hasta el momento no ha sido muy prolífero en trabajos históricocontables. 
Análisis de las discrepancias económicas entre Swanston y Cia, constructora del Puerto de la Luz (Canarias), y su ingeniero Juan de León y Castillo

2. RELACIÓN CONTRACTUAL ENTRE JUAN DE LEÓN Y CASTILLO Y LA SWANSTON Y CIA: ANÁLISIS DE SUS CONSECUENCIAS ECONÓMICAS

El 9 de marzo de 1891 Juan de León y Castillo cesa en la Jefatura de Obras Públicas de la Provincia con motivo de su ascenso al Cuerpo de Ingenieros de Caminos, Canales y Puertos como Inspector de $2^{a}$, dicho puesto le obligaba a residir en Madrid, pero su mala salud le impide tomar posesión del cargo de vocal de la Junta Consultiva del ramo y solicita, con fecha 7 de abril de ese mismo año, una prórroga de 30 días. No obstante, esta situación continúa y se le concede la baja por enfermedad que se prolongó durante más de un año ${ }^{1}$.

Por otra parte, como consecuencia de las discrepancias políticas con su hermano Fernando de León y Castillo, también en marzo del mismo año se separa de la dirección de la política local, jefatura que había ostentado hacia más de 20 años. Este acontecimiento le marco profundamente al sentirse aislado y sin apoyos influyentes.

Con este escenario político, profesional e incluso personal se encuentra Juan de León y Castillo cuando emprende un viaje a Londres, en abril de 1891, donde los Sres. Swanston y Cia. contratistas de las obras del Puerto le proponen la dirección facultativa de las mismas, ofrecimiento que acepta bajo las condiciones detalladas en el contrato privado firmado por los Sres. Swanston en Londres el 24 de julio de 1891 y por Juan de León y Castillo el 23 de octubre de ese mismo año.

Previamente a la redacción del contrato ambas partes establecieron unas bases que servirían para la confección del mismo. Algunas de estas bases las conocemos a través de la correspondencia surgida entre Juan de León y Castillo y José Miller, dirigente, éste último, junto con Juan Swanston de las oficinas de la Swanston y Cia. en Londres. En concreto, en la carta fechada el 8 de agosto de 1891 Juan de León y Castillo plantea los puntos del contrato, con los que no está de acuerdo comparándolo, para ello, con las bases convenidas anteriormente. Por ello, a continuación se detallan las citadas bases que ocasionaron el conflicto contractual.

La primera de estas bases estipulaba que tan pronto como las utilidades, es decir los beneficios obtenidos en el desarrollo de la actividad

Archivo Histórico Provincial de Las Palmas (AHPLP), Fondo documental Juan de León y Castillo (1852-1916), registro 17. 
contratada, compensasen el desembolso inicial constituido en Madrid por los Sres. Swanston (en adelante depósito), se dividirán estos sobrantes entre los interesados deducido previamente un $5 \%$ en concepto de tributos. Quedando en garantía para cubrir cualquier pérdida imprevista el citado depósito junto con las instalaciones en curso.

La condición cuarta de las bases citadas establecía que el ingeniero podía retirar a cuenta de su remuneración hasta la cantidad de $£ 1.000$ anuales con un interés del $5 \%$ mientras no hubiese sobrantes suficientes para distribuir, dichos adelantos serían descontados cuando se realizasen los primeros repartos.

También en las bases previas se indica que no se constituye sociedad, quedando la contabilidad y administración a cargo de los Sres. Swanston, teniendo que conformarse todos los partícipes con las cuentas y liquidaciones presentadas por dichos señores.

Llegados a este punto, se hace necesaria la trascripción del contrato para posteriormente exponer las discrepancias mostradas por Juan de León y Castillo entre ambos documentos -bases previas y contrato-.

Habiendo el señor D. Juan de León y Castillo cesado en el destino de Ingeniero Jefe de la Provincia de Canarias y estando con licencia del Gobierno y pudiendo por lo mismo encargarse de obras particulares, y los Sres. Swanston y Cia., contratistas de las obras del Puerto Refugio de La Luz, deseando aprovechar la inteligencia como Ingeniero e influencias como hombre político del dicho Sr. D. Juan de León y Castillo han convenido el contrato siguiente:

$1^{\circ}$. Nombrar desde el 19 de julio del corriente al Sr. D. Juan de León y Castillo Ingeniero Director y Consultivo en las Obras del Puerto de Refugio para dirigir los trabajos en todo o concerniente a dicho ramo, levantar los planos necesarios, etc., en los términos y con las condiciones del contrato con el Gobierno.

$2^{\circ}$. Dicho Sr. D. Juan de León y Castillo se obliga a emplear todo el influjo que posee y el de sus amigos tanto en Canarias como en Madrid para el mejor y más rápido desarrollo de dichas obras en conseguir los Certificados mensuales en Canarias y el pago de las mismas a la mayor brevedad y allanar las dificultades que puedan presentarse.

$3^{\circ}$. En remuneración de los servicios estipulados en las condiciones $1^{\mathrm{a}}$ y $2^{\mathrm{a}}$, los Sres. Swanston y Cia. darán al Sr. León y Castillo en efectivo una suma equivalente a la tercera parte de las utilidades netas que se obtengan de 
las dichas Obras del Puerto Refugio desde $1^{\circ}$ de julio hasta su terminación.

$4^{\circ}$. No siendo posible verificar en el día una liquidación exacta convienen las dos partes contratantes en fijar las utilidades obtenidas hasta la fecha en $€$ 18.000 (diez y ocho mil libras esterlinas) por lo cual el Sr. León y Castillo sólo tiene derecho a la tercera parte de las utilidades que arroje la liquidación final o la que bajo la cláusula $8^{\mathrm{a}}$ ha de levantarse en caso de su muerte, deduciendo de ella las mencionadas $€ 18.000$.

$5^{\circ}$. Todos los gastos que se hayan incurrido y puedan aún incurrirse hasta la terminación de las obras o hasta la terminación de este contrato según cláusula $8^{\mathrm{a}}$, en consultas, trabajos de otros Ingenieros, etc., así como ciertos gastos de índole reservada referente a la inspección de las obras y para el debido cumplimiento de las condiciones $1^{\text {a }}$ y $2^{\text {a }}$ serán de la exclusiva cuenta del Sr. León y Castillo y se deducirán de la tercera parte de utilidades que le correspondan por condiciones $3^{\mathrm{a}}$ y $4^{\mathrm{a}}$.

$6^{\circ}$. Como no puede averiguarse con exactitud los beneficios resultantes hasta la terminación final de las obras, y su entrega al Gobierno, se ha convenido en repartir en las proporciones indicadas el balance que haya hasta el día 30 de junio de cada año a favor de las dichas obras en la cuenta corriente que llevan los Sres. Swanston y Cia. con las mismas en Londres.

Si el dicho balance fuese más de $€ 3.000$ (tres mil libras esterlinas) sólo se repartirán $€ 3.000$, quedando el sobrante para formar una cuenta de Reserva para hacer frente a cualquiera eventualidad contraria.

$7^{\circ}$. En caso de ausencia permanente o incapacidad del Sr. León y Castillo imposibilitándole cumplir las condiciones $1^{\mathrm{a}}$ y $2^{\mathrm{a}}$ de este contrato los Sres. Swanston y Cia. tendrán el derecho de nombrar un sustituto por cuenta y a costos del Sr. León y Castillo.

$8^{\mathrm{a}}$. Este contrato es absolutamente personal, y por tanto libre de toda intervención de terceras partes y en el caso de la muerte del Sr. León y Castillo cesa en el acto, y sus herederos solamente tendrán derecho a percibir la parte correspondiente de utilidades habidas y pendientes de pago en aquel día según liquidación que harán los Sres. Swanston y Cia. tan pronto como les sea posible y con la cual se han de conformar los interesados.

$9^{\circ}$. Aunque al Sr. León y Castillo se le remunera con una proporción de las utilidades no por eso se constituye Sociedad Mercantil de ninguna clase entre las partes contratantes, ni se le dá a dicho Sr. Intervención en la Contabilidad y Administración de las dichas obras, 
las que quedan como hasta hoy a cargo y dirección exclusiva de los Contratistas y de sus representantes.

$10^{\circ}$. Al Sr. D. Juan de León y Castillo se le enterará de la marcha que llevan las obras pero no tendrá derecho a exigir cuentas de ninguna clase y además se obliga desde luego a conformarse con las cuentas y liquidaciones que levanten los Sres. Swanston y Cia., los contratistas.

$Y$ en prueba de su conformidad firman ambas partes este convenio por duplicado, Londres y julio veinte y cuatro de mil ochocientos noventa y uno.

Swanston y $\mathrm{C}$

Las Palmas 23 de octubre de 1891

Adición A ruego del Sor. Don Juan de León y Castillo se ha convenido en anticiparle anualmente la suma de quince mil pesetas $(15.000)$ o sean seiscientas libras (£ $600)$ a cuenta de las $€ 1.000$ que le corresponde según la cláusula $6^{\mathrm{a}}$. Estos adelantos se harán en Las Palmas en sumas iguales de tres mil setecientas cincuenta pesetas (3.750) cada trimestre y el Sor. León y Castillo abonará un interés del $6 \%$ anual desde la fecha de la entrega hasta el de reembolso.

Las Palmas 23 de octubre de 1891

Swanston y $\mathrm{C}$

Juan de León y Castillo

Como puede observarse el contrato consta de diez cláusulas que versan sobre los siguientes temas: la persona de Juan de León y Castillo y el compromiso adquirido, remuneración y aspectos administrativos y contables. Del análisis de los artículos primero, segundo y séptimo se observa cómo Juan de León y Castillo no sólo fue requerido por sus conocimientos técnicos, como Ingeniero Director y Consultivo en las Obras del Puerto, sino también por sus conocidas influencias, tanto en Canarias como en Madrid, en lo social y en lo político.

Los aspectos relativos a la remuneración que recibiría Juan de León y Castillo son ampliamente tratados en el contrato, dedicándole cinco cláusulas y una adición. Finalmente, a los aspectos administrativos y contables se les dedica los dos últimos artículos, donde la Swanston fue contundente al dejar claramente especificado que no se crearía una sociedad mercantil entre las partes contratantes, decisión que implicaba la no intervención de Juan de León y Castillo en la administración y en la 
contabilidad de las obras del puerto, negándosele incluso la posibilidad de exigir cuentas.

Del análisis de la documentación disponible podemos afirmar que el ingeniero fue consciente de las diferencias existentes entre el contrato y las bases convenidas previamente, hechos que le llevaron a realizar una exhaustiva comparación entre ambos documentos al objeto de dar a conocer a la compañía contratista los perjuicios que le iban a ocasionar y proponer algunas soluciones.

Por tanto, una vez descrito a grandes rasgos el contrato, procede a continuación mostrar las citadas divergencias. Una de las primeras observaciones realizadas por Juan de León y Castillo se sustenta en la comparación entre la primera base inicial y la cláusula sexta del contrato. En la citada base se indicaba que el reparto de las utilidades se realizaría una vez cubierto el depósito constituido por la Swanston en Madrid como garantía de las obras del puerto. En cambio esta circunstancia no fue recogida en la cláusula sexta del contrato, por ello Juan de León y Castillo teme que en el momento de repartir el resultado periódico obtenido y materializado en la liquidez existente en la cuenta corriente que llevan los Sres. Swanston y Cia en Londres, se incluya de forma implícita el citado depósito, por tanto indica en la carta que esto es indispensable consignarlo en el contrato.

De acuerdo con lo expuesto hemos de señalar que el depósito, entendido como una fianza, se recuperará al finalizar las obras que garantiza, por tanto es lógico que no constase en las cláusulas del contrato definitivo. Ahora bien, se puede comprender el temor de Juan de León y Castillo a que la Swanston detrajera la cuantía del depósito del saldo a repartir, toda vez que se mencionaba en la primera de las bases iniciales.

Otra discrepancia entre las bases y las cláusulas del contrato detectada por Juan de León y Castillo hace referencia a la remuneración anual. Por su parte, en la cuarta base previa se fijaba una cuantía máxima a retirar por el ingeniero de $€ 1.000$ independientemente de la existencia o no de beneficios, mientras que en la cláusula sexta del contrato se condiciona el reparto a la obtención de utilidades.

En este sentido, creemos que Juan de León y Castillo no fue consciente de las implicaciones que ocasionaría la mencionada diferencia hasta que en el ejercicio económico de 1891-1892 solicita le sean transferidas las $€ 1.000$ y se encuentra con la negativa por parte de la 
Swanston quien le remite al contrato, puesto que, de acuerdo con el mismo, al no existir sobrantes no tenía derecho a exigir cuantía alguna. Ante estos hechos Juan de León y Castillo realiza la siguiente reflexión:

... tiene razón legalmente hablando; pero esta negativa me ha hecho pensar detenidamente en el contrato, cosa que debí hacer ahí y no hice, pues creí que era una mera fórmula que no había de producir cuestiones tratándose de amigos antiguos y de seriedad. Confieso que hice mal y les suplico que me dispensen tratándose pues de dejar garantizados mis intereses en lo futuro, debe tenerse en cuenta que este negocio ha de tardar de 10 a 12 años en ultimarse y que por entonces algunos de nosotros podía faltar, la casa de Vds podía pasar a otras personas extrañas, con quienes se han de entender yo o mis hijos (AHPLP, Fondo documental Juan de León y Castillo (1852-1916), registro 23).

Es evidente que la reflexión realizada por Juan de León y Castillo nos muestra a una persona honrada y confiada, pero que a su vez se da cuenta del error cometido al consentir ciertas cláusulas contractuales, que jurídicamente le vincularían de manera irrevocable.

Por tanto, consideramos que en este asunto Juan de León y Castillo cometió una negligencia importante y cuesta entender cómo pudo firmar un contrato que no le aseguraba una remuneración anual fija, sabiendo que había renunciado a su carrera administrativa y por tanto, no iba a contar con ningún otro ingreso, de ahí sus palabras me he quedado sin sueldo y necesito de esa cantidad para mi casa y otras atenciones. No obstante, una posible justificación del proceder del ingeniero estaría en la visión de futuro que tenía sobre la construcción del puerto en cuanto a los cuantiosos beneficios que generaría. Pero como toda actividad empresarial necesita de un periodo para poder recuperar los capitales invertidos sin olvidar el factor riesgo implícito en cualquier operación económica.

En este sentido, creemos que el ingeniero debería de haberse asegurado una cantidad fija en concepto de remuneración y otra cuantía variable en función de las utilidades que reportarían las obras de construcción del puerto, debiendo todo ello haberlo hecho constar en el contrato.

No obstante, para subsanar, en cierta media, esta situación Juan de León y Castillo propone a la Swanston adicionar al contrato la siguiente cláusula: 
D. Juan de León y Castillo podrá retirar a cuenta de sus ganancias hasta la cantidad de $€ 1.000$ anuales con interés del $5 \%$ mientras no hayan sobrantes suficientes para dividir según el particular $6^{\circ}$, entendiéndose que quedará sin efecto esta cláusula si por algún caso imprevisto, como suspensión de obras, que no sacará la empresa utilidades correspondientes, entendiéndose que estas entregas se descontaran de las primeras utilidades a repartir (Ibídem).

La respuesta de la Swanston a la expresada petición de Juan de León y Castillo, se corresponde con la cláusula adicionada al contrato y transcrita anteriormente junto con el mismo. De la comparación entre ambas -petición del ingeniero y adición- podemos afirmar que no se ajustó a lo solicitado ni en la cuantía a percibir anualmente ni en el interés a detraer sobre la misma hasta su reembolso, dado que la primera se redujo a $€ 600$ y el segundo aumentó a un $6 \%$. No obstante, el importe a percibir no se vinculó a la existencia de imprevistos tal y como él propuso, circunstancia que le benefició.

Otra reflexión, en cuanto a las diferencias entre las bases y el contrato, llevada a cabo por Juan de León y Castillo gira en torno al hecho de no haberse constituido una Sociedad Mercantil específica para la realización de las obras del puerto. Por tanto, en atención a las bases, la contabilidad y la administración de las citadas obras quedarían a cargo de la empresa contratista, conformándose los demás partícipes con las cuentas y liquidaciones dadas por la Swanston. Esta base fue calificada por Juan de León y Castillo de dura, muy dura pero la aceptó para evitar la intervención o quizás litigios en el día de mañana, pensando siempre que él recibiría los balances anuales sobre los que se determinarían las cuantías a repartir. Pero, las cláusulas $9^{a}$ y $10^{a}$ del contrato acotaron las expectativas de Juan de León y Castillo toda vez que expresaron de forma clara y contundente que no podría intervenir en la Contabilidad y Administración de las obras y que no tendría derecho a exigir cuentas de ninguna clase.

Además, Juan de León y Castillo se lamentaba de tener que esperar un largo periodo de tiempo para conocer el estado de la contabilidad, puesto que él estimaba que la conclusión de las obras no se produciría antes de doce o más años, e incluso se llegó a plantear qué ocurriría si las obras del puerto cambiaran de contratista, en este sentido se manifiesta con las siguientes palabras:

... podrá suceder que estos obren de mala fe. Sin dificultad ninguna me dicen a mi o a mis hijos "Las obras 
del Puerto no han dejado utilidad, o han dejado pérdidas; y tenemos que conformarnos después de 12 años de trabajos y servicios". Por ello, propone modificar la condición $10^{\mathrm{a}}$ del contrato de la siguiente forma: Al Sr. D. Juan de León y Castillo se le enterará de la marcha que lleven las obras y se le dará copias de los balances anuales (Ibídem).

Esta propuesta no ocasionó ningún cambio en la redacción del contrato, la explicación la encontramos en la propia normativa contable vigente, pues entendemos que la empresa contratista no estaba obligada a dar publicidad de su información contable.

De acuerdo con lo expuesto, se podrían justificar las modificaciones que propuso Juan de León y Castillo, dado que sus honorarios dependían de las liquidaciones anuales que realizaba la Swanston, es lógico que quisiera conocer los balances, entendidos como fiel reflejo de la situación patrimonial, para poder verificar las citadas liquidaciones. Pero la Swanston, como sociedad colectiva y por aplicación del Código de Comercio, no estaba obligada a entregar la información solicitada y además, es comprensible que se negara a mostrar sus balances puesto que reflejaban no solo las obras de construcción del puerto sino también otras actividades desempeñadas por la empresa. Ahora bien, si la Swanston hubiese llevado una contabilidad diferenciada, es decir, hubiese utilizado libros contables para reflejar exclusivamente todas las actividades relacionados con las obras del puerto, habría sido más factible acceder a la petición de Juan de León y Castillo al no verse implicada el resto de la información contable de la Swanston.

Finalmente, las diferencias manifestadas por el ingeniero entre el contrato y las bases iniciales y sus intentos de modificación, el mismo y su posterior adición no llegaron a buen fin puesto que se cerró tal y como la Swanston propuso a Juan de León y Castillo. No obstante, antes de firmar el contrato Juan de León y Castillo, decepcionado con las diferencias señaladas anteriormente, realiza la siguiente reflexión en una carta dirigida a José Miller:

Pensando detenidamente en él me permito acompañarle unas observaciones, que $\mathrm{V}$ ha de encontrar razonables. Con razón dirá $V$ que por que no las exprese oportunamente. Hay momentos de ofuscación que no se conciben. Creí que era una mera formula el contrato. No pensé en los 12 años de duración, aunque algo podía fallar en que Vs podían traspasar el negocio y sólo me 
fijé en que se trataba de VV y de mi, y cualquiera forma me pareció igual.

Hoy he reflexionado, y $\mathrm{V}$ tiene que convenir conmigo en que el contrato no me dá garantía ninguna y quedo a merced de los contratistas (V.V. ú otros) durante 12 años ó mas años por venir á pasar á que me digan: "no ha ganado nada ó se ha perdido y por lo tanto puede $V$ irse con Dios" [AHPLP, Fondo documental Juan de León y Castillo (1852-1916), registro 28].

A pesar de existir este definitivo vínculo contractual entre la Swanston y Juan de León y Castillo, él no cesó de exteriorizar a la empresa contratista todos y cada uno de los daños que le ocasionaban algunas de las cláusulas del contrato, principalmente la sexta, novena y décima, que a continuación analizamos. En cuanto a la sexta condición el perjuicio detectado gira en torno al tipo de interés que a Juan de León y Castillo se le aplicaba sobre los adelantos a cuenta de la remuneración que él recibía de las utilidades, mientras la sociedad contratista no sufría ningún tipo de gravamen por este concepto. Este trato diferenciado no fue conocido por el ingeniero hasta que con motivo del fallecimiento de Sr. Torman, representante de la Swanston en Las Palmas, se le encarga que atendiera a la administración de las obras. Dicho encargo le supuso a Juan de León y Castillo el poder tener acceso a la documentación contable que tanto había anhelado, solicitado y tantas veces le había sido denegada.

En este momento Juan de León y Castillo se familiariza con las anotaciones contables realizadas por la Swanston y detecta, tal y como él indica que:

... poco a poco pude notar en los asientos una marcada tendencia a perjudicarme y favorecer a los Sres. Swanston [...]. En esta forma he venido tomando los adelantos, creyendo que mis socios cobrasen las dos mil libras que les correspondían en las mismas condiciones, pero resulta de los libros que no pagan intereses por las grandes sumas que han venido teniendo en su poder y en cambio lo exigen cuando, como sucede ahora, su saldo es acreedor. A mí me han exigido el $6 \%$ por el adelanto de los 4 trimestres hasta fin de cada año [AHPLP, Fondo documental Juan de León y Castillo (1852-1916), registro 20].

Otro daño que Juan de León y Castillo observó y puso en conocimiento de ello a la Swanston es el relacionado con la cláusula sexta y su posterior adición, en torno a la equivalencia entre la libra esterlina y 
la peseta. Hemos de señalar que en el contrato firmado por ambas partes la unidad monetaria utilizada es la libra esterlina y se ha de recurrir a la adición para detectar el tipo de cambio, tal y como se deduce de las siguientes palabras: la suma de quince mil pesetas (15.000) o sean seiscientas libras ( $€$ 600). Por tanto, quedaba de esta forma implícita la relación entra ambas monedas, es decir, una libra esterlina equivalía a veinticinco pesetas.

Una vez señalado el tipo de cambio fijado es de resaltar que únicamente se le aplicaba a Juan de León y Castillo, toda vez que cobraba en la moneda nacional, pesetas, y los Sres. Swanston recibían libras esterlinas al valor del momento, tal y como expuso el ingeniero:

Este razonamiento es un juego de prestidigitación, las $€$ 2.000 que mis socios cobran en Londres se abonan a la cuenta corriente de los Sres. Swanston valen 50 mil ptas. mas el premio del cambio. Las mil que debo recibir aquí las calculan a 25 y sólo me entregan 25 mil [Ibídem].

Este proceder podía ocasionar resultados opuestos a las partes contratantes, puesto que si se producía un alza en la cotización de la libra esterlina beneficiaba exclusivamente a la Swanston, en caso contrario la parte contratante favorecida sería Juan de León y Castillo por tener un tipo de cambio fijado en la adición del contrato. Pero, de acuerdo con la documentación elaborada por Juan de León y Castillo a partir de los datos suministrados por la Swanston, la realidad fue que el ingeniero perdió poder adquisitivo dado que la cotización de la libra, normalmente, estuvo por encima de la fijada en el contrato durante el periodo analizado.

Desde nuestro punto de vista es incomprensible como una de las partes contratantes pudo establecer, y la otra admitir, una adición al contrato en la que se mezclaban dos monedas (pesetas y libras esterlinas) $y$, por tanto, fijar implícitamente un tipo de cambio fijo cuando éste fluctúa constantemente.

En relación a la novena cláusula las observaciones del ingeniero giraban en torno a la prohibición de intervenir en la administración y en la contabilidad, como lo demuestran sus palabras:

... se me negó toda intervención en la administración y en la contabilidad, pretextando que no querían cuestiones, sobre todo de mis herederos, si como podía suceder fallecía antes de terminar las obras. Confiando hasta lo absurdo en la honradez y respetabilidad de los Sres. Swanston, acepté tal exagerada imposición. Los 
hechos han venido a demostrar que hubo en ello propósito deliberado de explotarme para sacar adelante los negocios [Ibídem].

También la cláusula décima trata aspectos relacionados con la gestión administrativa de las obras del puerto de La Luz y Las Palmas. En este sentido las consideraciones realizadas por Juan de León y Castillo se centran, nuevamente, en la imposibilidad de acceder a la documentación contable, como así vuelve a poner de manifiesto en una carta dirigida a Juan Swanston, socio de la empresa contratista. En la citada correspondencia Juan de León y Castillo pide explicaciones, de forma amistosa, sobre diversas operaciones realizadas por la Swanston sin acudir a la vía judicial dado que al fin y al cabo, por aplicación de la cláusula décima del contrato, no tenía derecho a realizar ninguna alegación. Por ello, el propio ingeniero afirma que:

... cuando se redactó el contrato no dí importancia á dicha condicion $10^{\mathrm{a}}$, porque la fama y respetabilidad de la casa de UU fue mi única garantia. Sin esta confianza, hubiese sido un acto de locura aceptarla.

Creí entonces que el objeto de UU al consignarla era un lujo de precauciones para evitar en absoluto cuestiones, pero nunca pensé que aprovechandose de dicha condicion se habrian de negar á explicar y aclarar operaciones que considero que lastiman mis derechos. Tal conducta podría hacer creer que premeditadamente se incluyó en el contrato [AHPLP, Fondo documental Juan de León y Castillo (1852-1916), registro 27].

Como puede deducirse de las palabras de Juan de León y Castillo, transcritas, son constantes las quejas que expone de las actuaciones realizadas por la compañía Swanston, en cuanto a la aplicación del contrato, invocando la confianza depositada en la citada compañía, basándose en su buena fama y prestigio, y en definitiva en la buena voluntad que esperaba de ella en la relación que les unía, como era la dirección de las obras del puerto.

Una vez expuestas y analizadas las objeciones a las cláusulas del contrato por parte de Juan de León y Castillo, la compañía Swanston respondió al ingeniero en una carta ${ }^{2}$, con fecha 27 de agosto de 1891, cuyo remitente fue José Miller, socio de la empresa contratista. En la

2 AHPLP, Fondo documental Juan de León y Castillo (1852-1916), registro 28. 
misma trata de contestar a las observaciones realizadas por Juan de León y Castillo, precisando que muchas de sus observaciones no las considero bien fundadas y otras fundadas sobre bases equivocadas.

En cuanto a la falta de garantía contractual, presente y futura, alegada por Juan de León y Castillo, la compañía Swanston responde que si dicho contrato no tiene valor no sé de que manera pueda tratarse un arreglo que tenga mas fuerza legal tanto para las partes contratantes como para sus sucesores. La respuesta de la Swanston entendemos que es lógica, el problema radica no en la validez legal o no del mismo, sino en algunas de sus cláusulas que Juan de León y Castillo, con el paso del tiempo reflexiona sobre sus implicaciones y se arrepiente de haber aceptado.

Con respecto a la preocupación de Juan de León y Castillo de un posible cambio en la titularidad de la empresa concesionaria de las obras del puerto, la Swanston responde que sería muy improbable y en el caso de producirse las obligaciones de esta quedarían en fuerza hacia sus sucesores, es decir los compromisos que emana del presente contrato serían asumidas por la nueva empresa contratista.

Ante la actitud catastrofista manifestada por el ingeniero al plantear que al finalizar las obras, transcurridos diez o doce años, no se produciría beneficio alguno, Swanston señala de forma sensata que mejor será que nada diga sobre este particular. Encontramos totalmente contradictorio el planteamiento realizado por Juan de León y Castillo, puesto que partimos de la base de que él consideraba rentable este negocio de construcción del puerto, hasta tal punto que firmó un contrato cuya remuneración estaba en función de los beneficios futuros que generaría.

La solicitud de Juan de León y Castillo de percibir las libras esterlinas correspondientes al ejercicio económico 1891-1892 fue rechazada por la empresa contratista, argumentando "que no es justo que Vdm quiera ahora exigir otro dividendo cuando no lo hay" [Ibídem]. Con esta respuesta se evidencia el problema de base que existía entre las partes contratantes, toda vez que la Swanston consideraba a Juan de León y Castillo como un socio, en cuestiones relacionadas con su remuneración, y como tal pensó en retribuirle en función de los beneficios existentes, de ahí el utilizar en esta respuesta el término dividendo. Mientras que, el ingeniero como personal contratado para dirigir las obras del puerto demandaba una cuantía anual fija como remuneración a los servicios que prestaba. 
También se pone de manifiesto el problema de base señalado anteriormente, la doble consideración del ingeniero como socio o trabajador en función de los intereses de la empresa contratista, cuando Juan de León y Castillo propuso retirar anualmente hasta 1.000 libras esterlinas independientemente de la existencia o no de utilidades y la compañía le responde no veo como esto pueda llevarse a cabo sin que los otros socios hagan lo mismo. Es evidente que en las palabras utilizadas por la Swanston queda demostrado nuevamente el tratamiento dado, en este caso, a Juan de León y Castillo como socio y de ahí que le planteen que si el retira cantidades también le corresponderá hacerlo a los demás socios e incluso le preguntan si se diese el caso de que no hay beneficios suficientes ¿quién ha de desembolsar las sumas necesarias?. Con este interrogante la Swanston trata de trasladar un problema societario a Juan de León y Castillo al objeto de no remunerarle si no hay resultados positivos, por aplicación de la cláusula sexta del contrato, mientras que el ingeniero sólo perseguía asegurarse un salario anual fijo, tal y como se ha señalado con anterioridad.

Esta respuesta de la Swanston entendemos que se justifica por los escasos resultados obtenidos hasta el momento, como se deduce de las palabras utilizadas en su correspondencia:

... por el resultado obtenido hasta la fecha hay que
desengañarse que las ilusiones que Vmd tiene formadas
son exageradas y que habrá que modificarlas y fundarlas
sobre hechos. Ya llevamos 8 años de trabajo y de la
parte de obra mas fácil y beneficiosa y ¿cual ha sido el
resultado? $€ 15.000$ escasas de beneficio en los 8 años
sease menos de $€ 3.000$ por año. Ya lo estuviera yo
equivocado y que las ganancias fueren mas de $€ 3.000$ al
año pero yo juzgo el futuro por el pasado en esto
[lbídem].

A la solicitud de Juan de León y Castillo de disponer de los balances y cuentas correspondientes a las obras del puerto, es rotunda la negativa de la empresa contratista e incluso apreciamos que de forma irónica le indican tampoco vemos la necesidad de ello pues si Vmd ve los libros y las cuentas que mas puede Vmd decir para informarse de la marcha del negocio [Ibídem]. Se podría deducir de las palabras transcritas que la compañía Swanston daba por hecho que el ingeniero no sería capaz de entender los registros contables, hipótesis que a lo largo de este estudio queda evidencia la no validez de la misma. 
Finalmente, la única propuesta aceptada por la Swanston, a las sucesivas sugerencias de Juan de León y Castillo para cambiar algunas cláusulas, es la relativa a la remuneración por los servicios que presta el ingeniero al señalar:

... esta es una propuesta que creo pueda tomarse en consideración pero no sobre la base de $€ 1000$ por año que Vmd dice puesto que no le corresponden según el arreglo presente á menos que hayan beneficios de $€$ 3.000 y [...] además si Vmd se evita todo riesgo que pueda haber en los trabajos de las Obras esta ventaja habría que tomarse en cuenta al fijar un sueldo fijo anual [Ibídem].

Observamos que la Swanston accede a concederle una remuneración anual, pero esta cuantía sería menor que la fijada en el contrato toda vez que en el mismo se le consideraba como socio, lo cual implicaba un riesgo inherente a la obtención o no de beneficios. Esta propuesta fue adicionada al contrato como ya fue expuesta con anterioridad.

De todo lo expuesto, podríamos sintetizar que la relación contractual entre Juan de León y Castillo y la compañía Swanston fue más allá de la mera relación que otorga todo contrato como consecuencia de la vinculación personal que ya existía entre ambos. Esta circunstancia llevó al ingeniero, como así lo confirman sus palabras ya referidas, a no ser demasiado exhaustivo en la revisión de las diferentes cláusulas contractuales dado que se trataba de un contrato entre amigos y con una empresa de reconocido prestigio. Precisamente, esta actitud benévola se tornó en su contra ocasionándole los perjuicios económicos expuestos en el presente trabajo.

\section{CONCLUSIONES}

La existencia del fondo documental que ha servido de fuente primaria para la realización de este trabajo se debe, casi exclusivamente, a la inquietud de Juan de León y Castillo al aceptar ser director de las obras del puerto y observar los perjuicios económicos que derivaban del vínculo contractual existente con la compañía contratista. Pues, de otra manera no habría dado lugar a que el ingeniero dispusiera de estos documentos, pasaran a formar parte de su propiedad y llegaran hoy en día a nuestras manos. 
Hemos de señalar que efectivamente existieron divergencias entre algunas de las bases previas al contrato, las conocidas por la documentación disponible, y el propio contrato. Estas discrepancias afectaban de forma negativa a los intereses particulares de Juan de León y Castillo, por ello nos preguntamos ¿cómo el ingeniero pudo aceptar las cláusulas y firmar el citado contrato, basándose por una parte, en la confianza depositada en la Swanston y por otra, en su buena voluntad evitando posibles litigios?

No obstante, ante esta situación Juan de León y Castillo no cesó en el intento de modificar las cláusulas del contrato, analizando el mismo y los datos contables de los que pudo disponer, observando los registros y detectando irregularidades, actividad que le califica de censor contable como consecuencia de la búsqueda de sus propios intereses. Por su parte, la Swanston, como toda empresa que busca el lucro y defiende sus intereses, se mantuvo firme en su posición y tan sólo admitió la adición que beneficiaba al ingeniero asegurándole unos honorarios fijos e independientes de los resultados obtenidos.

Asimismo, hemos de manifestar que para la redacción del contrato la empresa contratista tuvo un tratamiento diferenciado con la figura del ingeniero, en atención a sus propios intereses dado que en las cláusulas relacionadas con los aspectos retributivos, consideró a Juan de León y Castillo como socio de la empresa, al retribuirle en función de los beneficios esperados. En cambio, en otras cláusulas se aseguró de no considerarle como socio, puesto que se le negó, de forma expresa, el acceso a la información económica, administrativa y contable, al tener que conformarse con las liquidaciones que se obtendrían. Este fue el verdadero trasfondo de todas las quejas planteadas por el ingeniero tras la firma del contrato por parte de la Swanston, lo que derivó en sucesivas reflexiones y vanos intentos por cambiar algunas de las cláusulas.

\section{BIBLIOGRAFÍA}

BuRRIEL de ORUeTA, E.L. (1974) "El puerto de la Luz en Las Palmas de Gran Canaria", Boletín $n^{\circ} 18$ del Centro de Investigación Económica y Social de la Caja Insular de Ahorros de Gran Canaria. 
Delauny, J.M. y F. Quintana Navarro (1982) "Inventario del Fondo Documental de los hermanos León y Castillo", Actas del $V$ Coloquio de Historia Canario-Americana. Las Palmas de Gran Canaria, pp. 553-600.

HERNÁNDEZ GUTIÉRREZ, A.S. (1991) El puerto de la Luz en la obra de Juan de León y Castillo. Las Palmas de Gran Canaria: Escuela Universitaria Politécnica.

- (1995) Juan de León y Castillo: ingeniero, científico y humanista. Las Palmas de Gran Canaria: Gobierno de Canarias.

- (2006) Biografías de Científicos Canarios. Juan de León y Castillo. Las Palmas de Gran Canaria: Oficina de Ciencia, Tecnología e Innovación del Gobierno de Canarias.

MARTín DEL CASTILLO, J.F. (1987) Semblanzas africanas de Juan de León y Castillo, 1883. Las Palmas de Gran Canaria: Cabildo Insular de Gran Canaria.

- (1993) Ciencia y política en el pensamiento de Juan de León y Castillo. Las Palmas de Gran Canaria: Cabildo Insular de Gran Canaria.

- (1993) "Juan de León y Castillo y las Sociedades científicas, literarias, artísticas o de recreo de su tiempo", Anuario de Estudios Atlánticos, 39, pp. 401-430.

- (1995) "Ingeniería en Canarias, 1850-1900: Juan de León y Castillo", Boletín Millares Carlo, $\mathrm{n}^{\circ}$ 14. Las Palmas de Gran Canaria: Centro Asociado a la UNED.

- (1997) "Un 'aparato de gasolina' (¿1863?) diseñado por Juan de León y Castillo para el alumbrado de Las Palmas de Gran Canaria", A. MILLARES Cantero, M. Lobo Cabrera y P. Atoche Peña (coords.) Homenaje a Celso Martín de Guzmán (1946-1994). Universidad de Las Palmas de Gran Canaria, pp. 231-238.

- (2003) "El ingeniero Juan de León y Castillo y los ferrocarriles de Barcelona (1886-1890)", Transportes, Servicios y Telecomunicaciones, 6, pp. 167-180.

- (2003) "Juan de León y Castillo: planos para una historia iconográfica de la ingeniería canaria: aproximación al diseño técnico del siglo pasado", El Museo Canario, 58, pp. 229-264.

Millares TORRES, A (1982) Biografías de Canarios célebres. Las Palmas de Gran Canaria: Edirca.

MORENo, J.C. (1947) De los puertos de la Luz y Las Palmas y otras historias. Las Palmas de Gran Canaria: Gabinete Literario. 

del Puerto de la Luz (Canarias), y su ingeniero Juan de León y Castillo

SUÁREZ FALCón, Jordé (1952) El puerto de La Luz y los hermanos León y Castillo. Las Palmas de Gran Canaria: Tipografía Alzota.

TIPOGRAFíA DEL DiARIO (1909) El puerto de La Luz en Gran Canaria. Las Palmas de Gran Canaria. 